\title{
A relação da saúde com a qualidade do meio antrópico: \\ Uma questão de debate
}

\author{
Welington Fernandes Oliveira ${ }^{1}$ \\ Josenilde Chaves Pirola ${ }^{2}$ \\ Jorge Luiz de Góes Pereira ${ }^{3}$
}

RESUMO: Atualmente, a discussão sobre meio ambiente situa-se nas condições de sua sustentabilidade. Tal discussão decorre da deterioração da natureza e seus recursos nãorenováveis. Nesse paper, discutir-se-á a inter-relação da saúde humana com a qualidade do meio antrópico, através da revisão da literatura atual, apontando o resultado de pesquisas empíricas. Pode-se afirmar que a relação do Ser Humano com o meio ambiente está progredindo, à medida que o desenvolvimento deixa de ser econômico e busca-se preservar as condições de vida humana e do planeta. Nesse sentido, a idéia de saúde humana está diretamente atrelada à sustentabilidade ambiental, nas suas diferentes vertentes.

Palavras- chave: meio ambiente; saúde; sustentabilidade ambiental.

\section{INTRODUÇÃO}

Não é de hoje que as inter-relações entre população, recursos naturais e desenvolvimento têm sido objeto de preocupação social e de estudos científicos (HOGAN, 2002). Desde há muito, as exigências cada vez mais complexas da sociedade moderna vêm acelerando o uso dos recursos naturais, resultando em danos ambientais que colocam em risco a sobrevivência da humanidade e do planeta (SOUZA, 2004).

Como os seres humanos são dotados de percepção e consciência, eles têm grande responsabilidade, tanto em relação a si mesmos quanto à sociedade e ao ambiente: a de viverem de acordo com as leis da natureza. O gênero humano, idealmente, deveria ter consciência e percepção suficientes para viver de acordo com a ordem do Universo e colaborar com ela, sendo, dessa forma, livre para alcançar as mais altas possibilidades de evolução (VITHOULKAS, 1980).

Com isso, os recursos oriundos da natureza estão sendo aproveitados de forma predatória, causando graves danos ao meio ambiente e refletindo negativamente na própria condição de vida e de saúde do Ser Humano. Nesse sentido, Moraes (2004, p. 8) expõe que "tudo se tornou válido em nome do progresso, do bem estar da sociedade e da vida mais confortável". Mas, a busca do Ser Humano por uma vida melhor está Ihe trazendo doenças, problemas sociais e comprometendo seu futuro na Terra, já que suas ações são altamente degradantes. Desse modo, podemos afirmar que a questão ambiental assume relevância fundamental na atualidade, principalmente para os trabalhadores de saúde, pois o viver saudável depende intrinsecamente da qualidade de vida humana e ambiental. É o que afirma Porto e Freitas:

1 Mestrando do Programa de Pós-Graduação Stricto Sensu em Meio Ambiente e Sustentabilidade (UNEC), Caratinga, MG.

2 Mestrando do Programa de Pós-Graduação Stricto Sensu em Meio Ambiente e Sustentabilidade (UNEC),

Caratinga, MG.

3 Doutor e Professor do Centro Universitário de Carantinga (UNEC), Caratinga, MG. 
"[...] a saúde possui uma dimensão ética, social e cultural irredutível, sendo objeto de negociação e luta permanente dentro da sociedade, dependendo de como os valores, interesses e conflitos se relacionam dentro das estruturas de poder existentes, [...] a saúde também depende e se expressa em função dos recursos existentes no mundo material, físico e biológico, sendo impossível pensar a noção de saúde sem incorporar a dimensão ambiental que faz fortalecer ou enfraquecer a expressão da vida, humana ou não." (PORTO e FREITAS, 2002).

Essa é uma questão fundamental para repensarmos as mudanças de paradigmas que exigem a discussão da sustentabilidade ambiental, já que saúde está diretamente relacionada às condições de desenvolvimento das sociedades contemporâneas.

No cenário internacional, a Organização Mundial de Saúde (OMS) e a Organização Pan-Americana da Saúde (OPAS) criaram, em 1999, o conceito de Atenção Primária Ambiental, que é:

"[...] uma estratégia de ação ambiental, basicamente preventista e participativa em nível local, que reconhece o direito do ser humano de viver em um ambiente saudável e adequado, e a ser informado sobre os riscos do ambiente em relação à saúde, bem-estar e sobrevivência, ao mesmo tempo em que define suas responsabilidades e deveres em relação à proteção, conservação e recuperação do ambiente e da saúde." (OPAS, 1999, p. 28).

Em nível nacional, a definição de um conceito ampliado de saúde que apresenta a dimensão ambiental como um de seus determinantes coloca o desafio de reconhecer essa dimensão tanto na estruturação de discursos como de práticas que visem a promoção, proteção e recuperação da saúde.

Nesta situação, as decisões sobre ambiente e saúde em um país resultam, direta e indiretamente, de políticas econômicas ou sociais, que não podem ser consideradas de forma isolada. Principalmente as políticas ambientais que deveriam estar completamente associadas às outras políticas, tais como: saneamento, energia, recursos hídricos, habitação, indústria, agricultura, mineração e educação, no contexto do fortalecimento da democracia. Enfim, a saúde da população depende de sua inserção enquanto consumidores, trabalhadores ou moradores no ambiente (BRASIL, 2005).

Não é possível se falar de "sustentabilidade ambiental" sem mencionar a responsabilidade dos órgãos públicos na elaboração de políticas que contribuam para a garantia da qualidade de vida humana, já que, segundo Dallari (2005), o Estado tem o dever de assegurar a preservação de condições saudáveis para a vida e convivência dos seres humanos, impedindo a degradação da natureza e ambiental de qualquer espécie, que é uma necessidade da população. Isso não isenta a sociedade de participar dos processos decisórios que envolvam a elaboração de políticas públicas e nem de agir diretamente na melhoria da sua qualidade de vida. É um esforço que deve envolver toda sociedade organizada e não organizada.

Sendo assim, o presente artigo tem por objetivo discutir a relação entre saúde, meio ambiente e sustentabilidade ambiental, através de uma revisão atualizada da literatura e a citação de alguns estudos de caso. Entretanto, a discussão aqui proposta não esgota o debate, mas serve como uma reflexão para aqueles que se dedicam ao estudo da sustentabilidade ambiental, tendo como vertente a questão da saúde e a qualidade de vida das sociedades atuais, fenômeno em estudo e aumentando a familiaridade do pesquisador com o ambiente para estudos futuros mais precisos (GIL, 1994). 


\section{AS TRANSFORMAÇÕES DA RELAÇÃO DO SER HUMANO COM O MEIO AMBIENTE}

O mundo revela que o Ser Humano vem evoluindo do ponto de vista cultural, social, biológico e, principalmente, tecnológico, através de uma estreita relação com a natureza. $\mathrm{O}$ comportamento do ser humano, em relação ao meio ambiente e à natureza como fonte de recursos, era interpretado exclusivamente em termos da dimensão de equilíbrio, ou seja, a harmonia com o meio. Ênfase prevalecida por muito tempo na literatura.

Segundo Dorst (1973), o equilíbrio biológico natural entre o Ser Humano e a natureza desapareceu do mundo tão logo o caçador se transformou em pastor, e, sobretudo, em agricultor, sendo que, indubitavelmente, os problemas de conservação dos recursos naturais surgiram desde os primórdios da humanidade.

Durante as primeiras fases da história, o Ser Humano, talvez sem perceber, obedecia às leis gerais da ecologia e o crescimento demográfico era proporcional ao aumento de espaço e de alimentos disponíveis. No entanto, com os progressos técnicos aumentando, foram progredindo também os rendimentos pastoris e agrícolas e, paralelamente, as taxas populacionais foram crescendo desordenadamente (DORST, 1973).

De acordo com Ajzenberg e Barbosa (1992, p. 21),

"quatro séculos antes da era Cristã, Platão já lamentava o desflorestamento nas montanhas da Grécia. Em todos os períodos é possível encontrar o Ser Humano aproveitando os recursos da natureza, podendo assim garantir a subsistência humana."

Dessa forma, o Ser Humano vem manifestando percepções, ao longo do tempo, sobre sua ação com o meio ambiente. Segundo Dorst (1973, p. 1), "no âmbito da história da humanidade, algumas formas de degradação da natureza são, sem dúvida, antigas"; o próprio Ser humano primitivo já dispunha de um forte instrumento de poder, que era o fogo.

Deste modo, aquela suposta relação de equilíbrio do Ser humano com a natureza, que para alguns autores existia nos primórdios da história da humanidade, passou a ficar cada vez mais comprometida, sendo substituída por um processo de degradação ambiental, em escala progressivamente acelerada, principalmente com o desenvolvimento da ciência moderna, da tecnologia e da Revolução Industrial.

De acordo com Carvalho (2003), a partir da Revolução Industrial, nos meados do século XVIII, uma nova conotação foi vislumbrada sobre o ambiente e o seu uso, o que resultou em grandes transformações no meio ambiente físico, fortalecendo-se, no último século, com a tríade da produção: a natureza, o capital e o trabalho. No entanto, no início do século $X X$, uma nova tendência foi apresentada nesse cenário: a tecnologia, que trouxe mudanças que revolucionaram o mercado industrial, tanto na qualidade quanto na quantidade, e em tempo recorde na geração de bens industriais. Essas mudanças revolucionárias vieram impregnadas de grandes prejuízos sobre a saúde humana e a do planeta. Keith Thomas, no seu célebre livro "O dilema" (1988), mostra como as transformações ocorridas na Inglaterra do século XVII, com o desenvolvimento da cidade de Londres, impulsionada pela industrialização, trazem graves conseqüências sobre a saúde da população. Nessa época, Londres é marcada pela fumaça, pelo esgoto a céu aberto e também pela marginalização, violência e prostituição.

Pode-se dizer que o Ser Humano começou a se deparar com uma nova realidade ambiental, o que, juntamente com o avanço dos conhecimentos científicos, contribuiu para que começasse a perceber que ele próprio vem provocando um intenso desgaste no meio ambiente, principalmente em relação aos recursos naturais não-renováveis, de uma forma muito mais rápida do que o tempo necessário para a natureza se recompor, colocando todos diante da espantosa realidade de uma "terra limitada e deteriorada pelas várias sociedades que a povoam e exploram" (COIMBRA, 1985, p.26). Na verdade, o avanço

Revbea, Rio Grande, 6: 20-27, 2011. 
da ciência e a degradação ambiental dela resultante são conseqüência do paradigma cartesiano que transformou toda natureza em fonte inesgotável de recursos para satisfação das necessidades humanas. Necessidade essas criadas pela ideologia capitalista.

Atualmente, a Humanidade começa a perceber que a proteção ao meio ambiente é uma determinante de sua própria sobrevivência. Surgem, então, os grandes fóruns de discussão sobre as condições de vida do Homem e do planeta.

Foi a partir do século XIX que se observou a criação de organizações ambientalistas - em 1865, na Grã-Bretanha, seguida pelos Estados Unidos e África do Sul em 1883 e, já no século XX, a Suíça, em 1909. Nesse mesmo ano, os europeus reuniram-se no Congresso Internacional para Proteção da Natureza, em Paris, para analisar os progressos da proteção à natureza na Europa e sugeriram a criação de um organismo internacional de proteção à natureza. Assim, em 1913, criou-se a Comissão Consultiva para a Proteção Internacional da Natureza, assinada por 17 países. Com o começo da guerra, contudo, a Comissão foi esquecida (McCORMICK, 1992).

Com o passar dos anos, principalmente na década de 50 , surge o movimento ambientalista dos cientistas, que se preocupava com a poluição industrial dos rios.

Nos anos 60, o movimento ambientalista das ONGs começou a ganhar força mediante o grande número de obras literárias que divulgavam a preocupação com a degradação da natureza e também pelas freqüentes manifestações estudantis em defesa da natureza na Europa e nos Estados Unidos (McCORMICK, 1992).

Finalmente, no início de 1970, 300 mil americanos participaram do Dia da Terra, a maior manifestação ambientalista do planeta e que foi o ápice do novo ambientalismo. A partir de então, o ambientalismo começou a sofrer uma transformação, dando origem à Revolução Ambientalista norte-americana (McCORMICK, 1992).

Essa revolução fez crescer ainda mais a preocupação com a preservação do meio ambiente e a qualidade de vida. Esse novo ambientalismo era mais dinâmico, mais sensível, ativista e político. Tinha mais apoio público e considerava que a sobrevivência humana estava em jogo e que uma catástrofe ambiental só poderia ser evitada se houvesse mudanças nos valores e instituições das sociedades industriais.

Desse modo, foram sucessivas as ações tomadas para preservar o meio ambiente. Em 1971, a França criou o Ministério para a Proteção da Natureza e do Meio Ambiente, que levou vários outros países a se reorganizarem ou criarem departamentos ou órgãos responsáveis pela proteção ao meio ambiente. E, em 1972, aconteceu a Conferência das Nações Unidas, que reuniu 113 Nações em Estocolmo para discutir problemas do meio ambiente (CARVALHO, 2003). Foi a primeira vez que problemas políticos, sociais e econômicos do meio ambiente global foram discutidos num fórum intergovernamental com uma perspectiva de instituir ações corretivas.

Esse evento marcou a passagem do ambientalismo emocional da década de 60 para o ambientalismo mais racional dos anos 70. Resultou, também, na criação do Programa de Meio Ambiente das Nações Unidas, estabelecendo um compromisso entre as diferentes percepções de meio ambiente defendidas pelos países menos desenvolvidos e mais desenvolvidos. Esta última década é considerada a década do ambientalismo dos atores políticos estatais.

A década de 90 foi importante para o ambientalismo brasileiro, pois, até então, era um movimento que se preocupava com os problemas ecológicos, mas não os vinculava com a questão do desenvolvimento socioeconômico. Outro fator que ajudou na emergência do movimento ambiental ligado ao desenvolvimento socioeconômico foi a aceitação do conceito de desenvolvimento sustentável, expresso no Relatório Brundtland, de 1988 (MONTIBELLER FILHO, 2001). Entretanto, o enfoque do conceito de desenvolvimento sustentável ainda estava muito atrelado à garantia do desenvolvimento econômico como 
condição sine qua non para a sustentabilidade do planeta. Já no final dos anos 90 , o conceito de desenvolvimento sustentável é reformulado e passa a englobar também as vertentes sociais, culturais e políticas como fatores determinantes do desenvolvido e da qualidade de vida das sociedades atuais e futuras.

Conforme exposto anteriormente, para analisar a questão ambiental não se pode tomála isoladamente, pois ela apresenta relação e interdependência com outros elementos que envolvem a vida humana, suas condições e manifestações socioculturais e organizações políticas. Falar de sustentabilidade ambiental passou a ser sinônimo de qualidade de vida total, e isso envolve a saúde humana.

De acordo com Oliveira e Guimarães (2004, p. 27): "a interação e interdependência do meio ambiente, pressupõem superar o paradigma de dominação que sempre caracterizou as relações entre o ser humano e o meio ambiente", levando a uma re (significação) que potencialize a ética da alteridade, com ênfase em valores fundamentais. Este novo modelo de organização planetária deve ter como alicerce a responsabilidade, o cuidado e o respeito do ser humano para consigo mesmo, para com o próximo, para com as outras espécies e, até mesmo, para com os componentes abióticos que constituem a biosfera.

Portanto, não é possível conceituar o meio ambiente fora de uma visão de cunho antropocêntrico, pois a proteção jurídica daquele bem depende da ação humana. Tornase necessário, contudo, superar aquele modelo antropocêntrico e constituir um novo paradigma, no qual o ser humano faça parte da natureza.

Segundo Enrique Leff (2006), o desenvolvimento sustentável não se refere especificamente a um problema limitado de adequações ecológicas de um processo social, mas a uma estratégia ou modelo múltiplo para a sociedade, que deve levar em conta tanto uma viabilidade econômica quanto ambiental.

\section{SAÚDE E DESENVOLVIMENTO SUSTENTÁVEL}

A sustentabilidade como novo critério básico e integrador precisa estimular permanentemente as responsabilidades éticas, na medida em que a ênfase nas aspectos extra-econômicos serve para reconsiderar as características relacionadas com a equidade, a justiça social e a ética dos seres vivos. Além disso, as políticas públicas de saúde devem contemplar a questão da sustentabilidade ambiental.

A pesquisa de Loures (2008), desenvolvida no município de Muriaé/MG, mostra como é complicado conjugar o procedimento do Programa Saúde da Família (PSF) com as condições de infra-estrutura das famílias assistidas pelo programa. Segundo a autora, é difícil imprimir atos de higiene pessoal quando as populações carecem de atenção dos governos sobre os problemas ambientais onde residem. Em outras palavras, não se pode falar em saúde, educação e lazer, por exemplo, quando as politicas de saúde não estão atreladas a outras politicas públicas, como saneamento básico, pavimentação, transporte público e etc.

Segundo a autora (LOURES, 2008), melhorar a qualidade de vida das famílias que vivem à margem dos processos de desenvolvimento econômico é, ao mesmo tempo, melhorar os serviços de saúde prestados à população, como a Atenção Primária à Saúde. São as camadas populares que mais sofrem a falta de investimentos na área de saúde e infra-estrutura.

A pesquisa de Amorin (2007), por sua vez, aponta para a necessidade de se levar em consideração os aspectos relacionados à cultura local ao se tratar da questão da saúde reprodutiva das mulheres. Para a autora, ao se pensar em melhorar a qualidade de vida das mulheres da zona rural, devem-se considerar os seus preceitos religiosos, já que não se pode falar em desenvolvimento e saúde sem incorporar a questão dos costumes locais, os

Revbea, Rio Grande, 6: 20-27, 2011. 
saberes e valores que marcam a vida do lugar. Portanto, desenvolvimento, meio ambiente e saúde estão intimamente relacionados à cultura e à politica.

Segundo Laurell (1995), nas últimas décadas, houve na América Latina um "retrocesso social dramático", gerando o empobrecimento da população trabalhadora, além da incorporação de novos grupos sociais à situação de pobreza ou miséria. Ao mesmo tempo, reduziu-se consideravelmente os gastos sociais, o que indica também uma redução dos serviços sociais públicos, dificultando o acesso às necessidades básicas, como alimentação, habitação, saúde e educação, e contribuindo para deteriorar as condições de vida da maioria absoluta dessa população.

Dessa forma, o termo qualidade de vida tem se tornado um tema significativamente importante para a sociedade em geral, na literatura científica, e especialmente no campo da saúde, pois a progressiva desumanização, devido ao desenvolvimento tecnológico das ciências da saúde, trouxe uma maior preocupação com o tema (NUCCI, 2003; CÁRDENAS, 2004;).

Maricato (2006) ressalta que a participação da sociedade civil, por meio da representação dos diversos atores sociais, tem como garantir de forma legal a inclusão dos que, de alguma maneira, sentem-se fora das discussões sobre o futuro do país. Além disso, não se deve deixar de considerar que são vários os interesses do capitalismo global, incluindo aí a manipulação do Estado, mas devem-se articular novas redes de saberes, em busca de novas perspectivas nas ações conscientes em prol da coletividade. Dessa forma, percebe-se que novas posturas são necessárias frente às demandas vigentes sobre as condições da vida planetária e a sua manutenção por um meio saudável.

\section{CONCLUSÃO}

O meio ambiente é uma produção social que pode influenciar a saúde humana positiva ou negativamente, de maneira individual ou coletiva, direta ou indiretamente, o que torna a relação entre saúde e meio ambiente uma complexa relação entre Estado, natureza e sociedade. É dessa relação marcada por grandes contradições que surgem os riscos ambientais, considerados entre os grandes problemas da saúde coletiva hoje, já que afetam a qualidade de vida da população e, conseqüentemente, sua saúde.

Tornam-se incontestáveis as relações satisfatórias entre meio ambiente e saúde, na medida em que essas duas categorias apresentam interfaces que ampliam o escopo da discussão e do entendimento da complexidade da ocorrência do processo saúde/doença numa sociedade que adotou um modelo de desenvolvimento predatório e excludente, o que tem impactado quantitativa e qualitativamente a condição de saúde da população.

Desse modo, as questões sobre qualidade de vida precisam ser realmente discutidas para que se chegue a um consenso de que a sustentabilidade planetária depende diretamente de novas posturas de toda a humanidade, a começar principalmente com a sociedade civil por meio de seus diversos atores sociais. Identificar os elementos de insustentabildiade e refletir criticamente sobre o espaço de cada um no mundo, articulando possibilidades de agir em prol da sustentabilidade de forma decisória, apresentando possíveis soluções, avaliando alternativas, justificando as escolhas entre as variadas visões.

\section{REFERÊNCIAS}

AJZENBERG, E. M.; BARBOSA, A. M. T. B. Comunicação, arte e meio ambiente. In: MASSAMBANI, O.; CAMPIGLIA, S. S. (Org.). Meio ambiente e desenvolvimento: FORUM - Universidade de São Paulo. São Paulo, 1992. p.119 - 124. 
AMORIN, P. B. Gênero, sexualidade e saúde reprodutiva das mulheres neopentecostais moradoras da zona rural de Lajinha/Minas Gerais. Originalmente apresentado como dissertação de mestrado. Centro Universitário de Caratinga, UNEC, Caratinga, 2007.

BRASIL. Ministério das Cidades. Organização Pan-Americana da Saúde. Política e plano municipal de saneamento ambiental: experiências e recomendações. Programa de Modernização do Setor de Saneamento. Brasília: OPAS, 2005. 89 p.

CÁRDENAS, A. M. C. Qualidade de vida da mulher de uma comunidade de baixa renda: estudo comparativo entre mulheres com trabalho doméstico e trabalho remunerado. Originalmente apresentada como tese de doutorado em Enfermagem. Universidade de São Paulo, São Paulo, 2004. 156 p.

CARVALHO, C. G. O que é Direito Ambiental: Dos Descaminhos da Casa à Harmonia da Nave. Florianópolis: Habitus, 2003.

COIMBRA, J. A. A. O outro lado do meio ambiente. São Paulo: CETESB/ASCETESB, 1985.

DALLARI, D. A. Vigilância Sanitária é uma das expressões mais avançadas da afirmação do direito à saúde e da busca de sua efetivação.[Editorial].Revista Brasileira de Vigilância Sanitária. v.1, n.1, p. 1- 2, 2005

DORST, J. Antes que a natureza morra: por uma ecologia política. Tradução Rita Bongermino. São Paulo: Edgar Blucher, 1973.

GIL, A. C. Métodos e Técnicas de Pesquisa Social. 4 ed. São Paulo:Atlas, 1994.

HOGAN, D. J. Crescimento Populacional e Desenvolvimento Sustentável. São Paulo: [s.n.], 2002.

KEITH, T. O homem e o mundo natural. São Paulo: Companhia Das Letras, 1988.

LAURELL, A. C. Avançando em direção ao passado: a política social do neoliberalismo. In: Laurell, A. C. (Org.). Estado e políticas sociais no neoliberalismo. São Paulo: Cortez, 1995. p.151 - 178.

LEFF, E. Racionalidade ambiental e a reapropiação social da natureza. Rio de Janeiro: Record, 2006.

LOURES, S. L. C. S. Avaliação das condições de saúde e socioambientais das famílias, assistidas pelos PSF's nos bairros Santa Terezinha, Porto e Aeroporto, no município de Muriaé, MG. Originalmente apresentado como dissertação de mestrado. Centro Universitário de Caratinga, UNEC, Caratinga. 2008.

MARICATO, E.; SANTOS Jr., O. A. Construindo a Política Urbana: participação democrática e o direito a cidade. In: Teoria e Debate, n. 66, abr./jun, 2006.

McCORMICK, J. Rumo ao Paraíso: A História do Movimento Ambientalista. Rio de Janeiro: Relume-Dumerá, 1992.

MONTIBELLER-FILHO, G. O Mito do Desenvolvimento Sustentável. Florianópolis: UFSC, 2001. 
MORAES, M. E. B. A. Eficiência do Direito Penal Moderno para a Tutela do Meio Ambiente: Lei nº. 9.605/98. Rio de Janeiro: Lúmen Júris, 2004.

NUCCI, N. A. G. Qualidade de vida e câncer: um estudo compreensivo. Originalmente apresentado como tese de doutorado em Psicologia. Departamento de Psicologia e Educação da Faculdade de Filosofia, Ciências e Letras de Ribeirão Preto, Universidade de São Paulo, São Paulo, 2003. 225 p.

OLIVEIRA, F. P. M.; GUIMARÃES, F. R. Direito, Meio Ambiente e Cidadania. São Paulo: WVC, 2004.

ORGANIZAÇÃO PAN-AMERICANA DE SAÚDE - OPAS. Atenção primária ambiental. Washington, D. C: OPAS, 1999.

PORTO, M. F. S.; FREITAS, C. M. (Org.). Problemas ambientais e vulnerabilidade: abordagens integradoras para o campo de saúde pública. Rio de Janeiro: Fiocruz, 2002.

VITHOULKAS, G. Homeopatia: ciência e cura. São Paulo: Cultrix, 1980. 436 p. 